\title{
Mortality associated with tiotropium mist inhaler in patients with chronic obstructive pulmonary disease: systematic review and meta-analysis of randomised controlled trials
}

\author{
Sonal Singh, assistant professor, ${ }^{1}$ Yoon K Loke, senior lecturer, ${ }^{2}$ Paul L Enright, professor, ${ }^{3}$ Curt D Furberg, \\ professor $^{4}$
}

\begin{abstract}
'Department of Medicine, Johns
Hopkins University School of

Medicine, 1830 E Monument

Street, Baltimore, MD 21287, USA

${ }^{2}$ School of Medicine, Health Policy and Practice, University of East Anglia, Norwich, UK

${ }^{3}$ College of Public Health, University of Arizona, Tucson, AZ, USA

${ }^{4}$ Division of Public Health Sciences, Wake Forest University School of Medicine, Winston-

Salem, NC, USA

Correspondence to: $\mathrm{S}$ Singh ssingh31@jhu.edu

Cite this as: $B M J$ 2011;342:d3215 doi:10.1136/bmj.d3215
\end{abstract}

\begin{abstract}
Objective To systematically review the risk of mortality associated with long term use of tiotropium delivered using a mist inhaler for symptomatic improvement in chronic obstructive pulmonary disease.
\end{abstract}

Data sources Medline, Embase, the pharmaceutical company clinical trials register, the US Food and Drug Administration website, and ClinicalTrials.gov for randomised controlled trials from inception to July 2010. Study selection Trials were selected for inclusion if they were parallel group randomised controlled trials of tiotropium solution using a mist inhaler (Respimat Soft Mist Inhaler, Boehringer Ingelheim) versus placebo for chronic obstructive pulmonary disease; the treatment duration was more than 30 days, and they reported data on mortality. Relative risks of all cause mortality were estimated using a fixed effect meta-analysis, and heterogeneity was assessed with the $\mathrm{I}^{2}$ statistic.

Results Five randomised controlled trials were eligible for inclusion. Tiotropium mist inhaler was associated with a significantly increased risk of mortality (90/3686 v 47/2836; relative risk $1.52,95 \%$ confidence interval, 1.06 to $\left.2.16 ; P=0.02 ; I^{2}=0 \%\right)$. Both $10 \mu g$ (2.15, 1.03 to $\left.4.51 ; P=0.04 ;\left.\right|^{2}=9 \%\right)$ and $5 \mu g(1.46,1.01$ to 2.10 ; $\mathrm{P}=0.04 ; \mathrm{I}^{2}=0 \%$ ) doses of tiotropium mist inhaler were associated with an increased risk of mortality. The overall estimates were not substantially changed by sensitivity analysis of the fixed effect analysis of the five trials combined using the random effects model $(1.45,1.02$ to 2.07; $\mathrm{P}=0.04$ ), limiting the analysis to three trials of one year's duration each $(1.50,1.05$ to 2.15$)$, or the inclusion of additional data on tiotropium mist inhaler from another investigational drug programme $(1.42,1.01$ to 2.00$)$. The number needed to treat for a year with the $5 \mu \mathrm{g}$ dose to see one additional death was estimated to be 124 (95\% confidence interval 52 to 5682) based on the average control event rate from the long term trials.

Conclusions This meta-analysis explains safety concerns by regulatory agencies and indicates a $52 \%$ increased risk of mortality associated with tiotropium mist inhaler in patients with chronic obstructive pulmonary disease.

\section{INTRODUCTION}

Chronic obstructive pulmonary disease is ranked the fourth leading cause of death worldwide, with an estimated 3.02 million in $2004 .{ }^{1}$ Inhaled tiotropium bromide, a long acting anticholinergic drug, is approved for symptomatic benefit in patients with chronic obstructive pulmonary disease. The treatment benefit of inhaled tiotropium is a reduction in both the symptoms of dyspnoea and the risk for exacerbations of chronic obstructive pulmonary disease. ${ }^{2}$

Inhaled tiotropium is available in two formulations: as a powder (Spiriva; Boehringer Ingelheim, Germany) delivered with a Handihaler device (Boehringer Ingelheim) and in solution as a mist delivered with the Respimat Soft Mist Inhaler (Boehringer Ingelheim). The mist inhaler is a propellant free device, which generates a fine, slow moving cloud for inhalation. ${ }^{3}$ The delivered dose is independent of inspiratory effort and relatively unaffected by problems with breathing manoeuvre compared with other devices. It is recommended for use in patients who have poor manual dexterity and therefore have difficulty using the Handihaler. ${ }^{4}$ Pharmacokinetic studies have shown that compared with tiotropium $18 \mu \mathrm{g}$ delivered by the Handihaler, peak plasma concentrations with the mist inhaler at doses of $5 \mu \mathrm{g}$ and $10 \mu \mathrm{g}$ were $35 \%$ and threefold higher, respectively. ${ }^{3}$ The mist inhaler is available in 55 countries (320 000 prescriptions compared with 3 million for tiotropium powder dispensed in England and Scotland in 2009), ${ }^{56}$ but this formulation has yet to gain regulatory approval in the United States. ${ }^{7}$

Cardiovascular disease is the leading cause of morbidity and mortality among patients with chronic obstructive pulmonary disease. ${ }^{8}$ The cardiovascular effects of inhaled anticholinergics have been evaluated in recent studies. ${ }^{29-15} \mathrm{~A}$ meta-analysis of 17 randomised controlled trials found a significantly increased risk of major cardiovascular events (stroke, myocardial infarction, and cardiovascular deaths, including sudden death) with inhaled anticholinergics (relative risk $1.58,95 \%$ confidence interval 1.21 to $2.06 ; \mathrm{P}<0.001){ }^{9}$ 
In this meta-analysis, the higher mortality rate in the group receiving inhaled anticholinergics did not reach significance (relative risk 1.26, 95\% confidence interval 1.0 to $1.61 ; \mathrm{P}=0.06$ ). However, the UPLIFT (Understanding the Potential Long-Term Impacts on Function with Tiotropium) trial of about 6000 patients compared tiotropium powder with placebo ${ }^{15}$ and did not report any increase in mortality or cardiovascular events. Some have considered data from that trial to be reassuring on the safety of tiotropium. ${ }^{16}$ Patients receiving tiotropium with the mist inhaler are, however, potentially exposed to higher concentrations and the powder and mist inhaler formulations are considered to be distinct products. ${ }^{7}$ In mid-December 2009 we came across documents on the US Food and Drug Administration website describing an advisory committee hearing on tiotropium, held on 19 November 2009. ${ }^{7}$ The main focus of this hearing was the safety of tiotropium powder, but we became aware of an accompanying discussion concerning a numerical imbalance favouring placebo in the mortality data for the tiotropium mist inhaler. In view of these concerns about safety we systematically reviewed and meta-analysed data from randomised controlled trials on the risk of mortality associated with inhaled tiotropium delivered by the mist inhaler compared with placebo in patients with chronic obstructive pulmonary disease.

\section{METHODS}

In early 2010 we proceeded with formulating a review question after finding out that tiotropium was licensed for use by mist inhaler (Respimat Soft Mist Inhaler; Boehringer Ingelheim) in Europe, and a review of mortality concerns would therefore be clinically relevant and warranted. Further discussion of the review design and protocol took place in the second quarter of 2010, based on the specific purpose of using typical systematic review and meta-analytical techniques to independently evaluate the numerical imbalance in mortality favouring placebo that had been discussed at the FDA hearing. Final consensus on the protocol was reached at the end of June 2010, and the conduct of this review as per protocol began in July 2010.

\section{Search strategy}

We searched Medline and Embase from inception to July 2010 (Ovid SP) using the search terms "tiotropium.mp" AND "respimat.mp" where the suffix mp indicates searching of the titles, abstracts, subject headings, substance name, and registry words. We did not specify any language or population restrictions. To identify unpublished studies we typed in the simple search terms "respimat and tiotropium" in the search boxes of several websites: Boehringer Ingelheim clinical trials register, the FDA, and ClinicalTrials.gov up to July $2010 .^{717-20}$ We also checked the bibliographies of included studies and other systematic reviews, which included looking at the included and excluded trials picked up by the PubMed clinical trial filter search for "tiotropium" from our previous metaanalysis. $^{9}$

\section{Study selection}

Trials were identified and checked against inclusion and exclusion criteria. Two reviewers (YKL and SS) independently scanned all titles and abstracts that indicated the study was a randomised controlled trial evaluating the use of tiotropium mist inhaler among patients with chronic obstructive pulmonary disease. After obtaining full reports of potentially relevant trials, the same reviewers independently assessed eligibility from full text articles. Studies were selected for inclusion if they were parallel group randomised controlled trials of tiotropium mist inhaler compared with placebo for the treatment of chronic obstructive pulmonary disease, if treatment duration was for at least 30 days, and if they provided numerical data on mortality.

\section{Study characteristics and quality and risk of bias assessment}

We used a prespecified protocol to record the location and duration of the randomised controlled trials (in years), the dose and frequency of tiotropium mist inhaler and placebo, mean age and sex of participants, mean forced expiratory volume in one second $\left(\mathrm{FEV}_{1}\right)$, and smoking status.

The Cochrane toolkit was used for the assessment of bias in evaluating each trial for the reporting of randomisation, allocation concealment, the use of blinding of participants and staff, and information on loss to follow-up or withdrawal rates. ${ }^{21}$ In accordance with the Cochrane handbook of systematic reviews, we assessed the quality of data on adverse effects by recording how they were monitored and recorded by the investigators. ${ }^{21}$

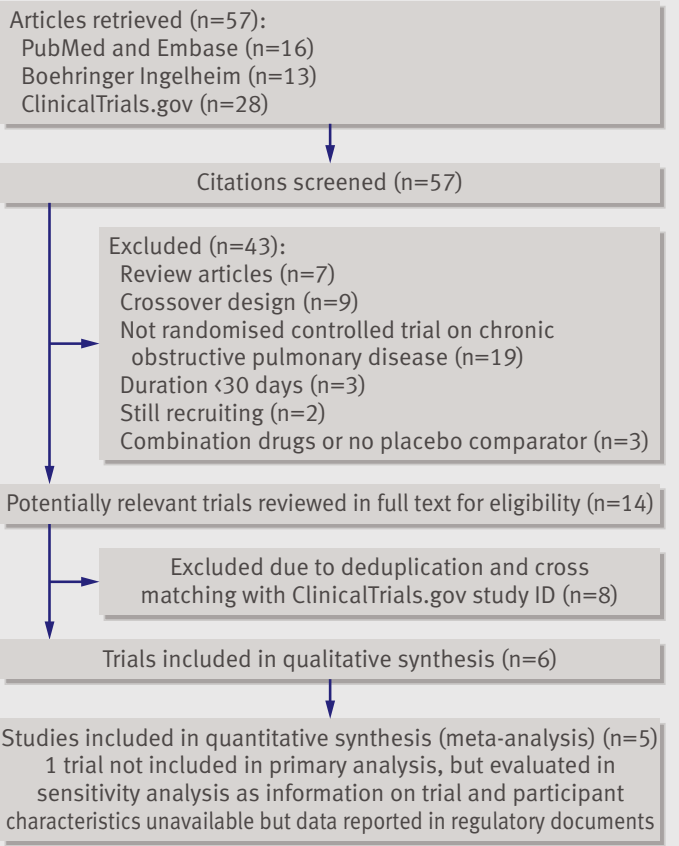

Fig 1| Flow of participants through review 
Table 1 |Characteristics of tiotropium mist inhaler* in randomised controlled trials included in analysis of mortality

\begin{tabular}{|c|c|c|c|c|c|c|c|c|c|c|}
\hline $\begin{array}{l}\text { Study } \\
\text { Source }\end{array}$ & Location & $\begin{array}{l}\text { Duration } \\
\text { (weeks) }\end{array}$ & Primary outcome & $\begin{array}{l}\text { Cardiac and other } \\
\text { exclusions }\end{array}$ & Drug and daily dose & $\begin{array}{l}\text { No of } \\
\text { partici- } \\
\text { pants }\end{array}$ & $\begin{array}{l}\text { Mean (SD) } \\
\text { age (years) }\end{array}$ & Males (\%) & $\begin{array}{l}\text { Mean (SD) } \\
\% \text { predicted } \\
\text { FEV }_{1}\end{array}$ & $\begin{array}{l}\text { Current } \\
\text { smokers } \\
(\%)\end{array}$ \\
\hline $\begin{array}{l}\text { Voshaar et al } \\
2008 \dagger^{2729}\end{array}$ & Multinational & 12 & $\mathrm{FEV}_{1}$ & $\begin{array}{l}\text { NA; condition that } \\
\text { could influence their } \\
\text { ability to participate } \\
\text { in study }\end{array}$ & $\begin{array}{l}\text { Tiotropium } 10 \mu \mathrm{g} \\
\text { (two puffs of } 5 \mu \mathrm{g} \\
\text { each); tiotropium } \\
5 \mu \mathrm{g} \text { (two puffs of } \\
2.5 \mu \mathrm{g} \text { each); } \\
\text { placebo }\end{array}$ & $93 ; 88 ; 91$ & $\begin{array}{l}64(9) ; 64 \\
(9) ; 63(9)\end{array}$ & $72 ; 69 ; 69$ & $\begin{array}{l}39(12) ; 40 \\
(12) ; 42(12)\end{array}$ & $37 ; 37 ; 43$ \\
\hline $\begin{array}{l}\text { Voshaar et al } \\
2008 \dagger^{2829}\end{array}$ & Multinational & 12 & $\mathrm{FEV}_{1}$ & $\begin{array}{l}\text { NA; condition that } \\
\text { could influence their } \\
\text { ability to participate } \\
\text { in study }\end{array}$ & $\begin{array}{l}\text { Tiotropium } 10 \mu \mathrm{g} \\
\text { (two puffs of } 5 \mu \mathrm{g} \\
\text { each); tiotropium } \\
5 \mu \mathrm{g} \text { (two puffs of } \\
2.5 \mu \mathrm{g} \text { each); } \\
\text { placebo }\end{array}$ & $87 ; 92 ; 90$ & $\begin{array}{l}64(9) ; 64 \\
(9) ; 63(9)\end{array}$ & $72 ; 69 ; 69$ & $\begin{array}{l}39(12) ; 40 \\
(12) ; 42(12\end{array}$ & $37 ; 37 ; 43$ \\
\hline $\begin{array}{l}\text { Bateman et al } \\
2010 \ddagger^{3032}\end{array}$ & Multinational & 52 & $\begin{array}{l}\mathrm{FEV}_{1}, \mathrm{FEV}_{1} \text { and } \mathrm{St} \\
\text { George's respiratory } \\
\text { questionnaire; } \\
\text { transitional } \\
\text { dyspnoea index and } \\
\text { exacerbation rate }\end{array}$ & $\begin{array}{l}\text { NA; excluded those } \\
\text { with disease who } \\
\text { might be at risk } \\
\text { because of } \\
\text { participation }\end{array}$ & $\begin{array}{l}\text { Tiotropium } 10 \mu \mathrm{g} \\
\text { (two puffs of } 5 \mu \mathrm{g} \\
\text { each); tiotropium } \\
5 \mu \mathrm{g} \text { (two puffs of } \\
2.5 \mu \mathrm{g} \text { each); } \\
\text { placebo }\end{array}$ & $\begin{array}{l}332 ; 332 ; \\
\quad 319\end{array}$ & $\begin{array}{c}64.6(8.4) ; \\
65(8.2) ; 64.7 \\
(8.9)\end{array}$ & $\begin{array}{c}75.9 ; 73.1 \\
79.3\end{array}$ & $\begin{array}{l}37.7 \text { (11.7); } \\
38.0 \text { (11.7); } \\
37.5 \text { (11.6) }\end{array}$ & $35 ; 38 ; 36$ \\
\hline $\begin{array}{l}\text { Bateman et al } \\
2010 \ddagger^{3132}\end{array}$ & Multinational & 52 & $\begin{array}{l}\text { Predose } \mathrm{FEV}_{1} \text { and } \mathrm{St} \\
\text { George's respiratory } \\
\text { questionnaire; } \\
\text { transitional } \\
\text { dyspnoea index and } \\
\text { exacerbation rate }\end{array}$ & $\begin{array}{l}\text { NA; excluded those } \\
\text { with disease who } \\
\text { might be at risk } \\
\text { because of } \\
\text { participation }\end{array}$ & $\begin{array}{l}\text { Tiotropium } 10 \mu \mathrm{g} \\
\text { (two puffs of } 5 \mu \mathrm{g} \\
\text { each); tiotropium } \\
5 \mu \mathrm{g} \text { (two puffs of } \\
2.5 \mu \mathrm{g} \text { each); } \\
\text { placebo }\end{array}$ & $\begin{array}{c}335 ; 338 \\
334\end{array}$ & $\begin{array}{l}65.6(8.6) ; \\
64.4(8.9) ; \\
65.7(8.4)\end{array}$ & $\begin{array}{l}73.4 ; 73.3 \\
\quad 70.3\end{array}$ & $\begin{array}{l}37.7 \text { (11.7); } \\
38.0 \text { (11.7); } \\
37.5 \text { (11.6) }\end{array}$ & $35 ; 38 ; 36$ \\
\hline $\begin{array}{l}\text { Bateman et al } \\
2010^{33} 34\end{array}$ & $\begin{array}{l}336 \text { outpatient } \\
\text { centres in } 31 \\
\text { countries }\end{array}$ & 52 & $\begin{array}{l}\text { Predose } \mathrm{FEV}_{1} \text { and } \\
\text { exacerbation }\end{array}$ & $\begin{array}{l}\text { Unstable } \\
\text { arrhythmias; } \\
\text { myocardial } \\
\text { infarction in past } \\
6 \text { months or } \\
\text { congestive heart } \\
\text { failure in past } \\
12 \text { months }\end{array}$ & $\begin{array}{l}\text { Tiotropium } 5 \mu \mathrm{g} \text { (two } \\
\text { puffs of } 2.5 \mu \mathrm{g} \text { each); } \\
\text { placebo }\end{array}$ & 1989; 2002 & $\begin{array}{l}64.8 \text { (9.1); } \\
64.8(9.0)\end{array}$ & $78 ; 77$ & $40 ; 40$ & $35.7 ; 35.9$ \\
\hline $\begin{array}{l}\text { 1205.14; } \\
\text { NC- } \\
\text { T00528996 }\end{array}$ & Multinational & 24 & Trough FEV $_{1}$ & NA & $\begin{array}{l}\text { Tiotropium } 5 \mu \mathrm{g} \text { (two } \\
\text { puffs of } 2.5 \mu \mathrm{g} \text { each); } \\
\text { placebo }\end{array}$ & $427 ; 429$ & $N A ; N A$ & NA; NA & NA; NA & $N A ; N A$ \\
\hline
\end{tabular}

$\mathrm{FEV}_{1}=$ forced expiratory volume in one second; $\mathrm{NA}=$ not available.

*Respimat Soft Mist Inhaler (Boehringer Ingelheim).

tData from studies $251^{27}$ and $252^{28}$ were pooled in Voshaar et al. ${ }^{29}$

†Data from studies $254^{30}$ and $255^{31}$ were pooled in Bateman et al. ${ }^{32}$

\section{Outcome measures}

The primary outcome measure was prespecified as mortality from any cause. As a post hoc secondary end point we evaluated deaths from cardiovascular causes (myocardial infarction, stroke, cardiac death, and sudden death).

\section{Data abstraction}

From the listings of safety data collected as part of adverse event reporting for each study, two reviewers (YKL and SS) independently and separately extracted data (including no events) on the proportion of patients who died. To avoid potential duplication we checked the regulatory reports with trials in the clinical trials register when possible. Data on mortality were extracted from regulatory documents and manufacturer's registry for trials that were unpublished. If a study had multiple reports, we preferentially extracted data from the version that had been reviewed or adjudicated by the regulatory authority. Two reviewers (YKL and SS) were independently involved in all stages of study selection, data extraction, and quality assessment. Discrepancies were resolved with $100 \%$ agreement after rechecking the source papers and further discussion among the reviewers, with full consensus before drafting the article. If required, we contacted authors for clarification on specific aspects of the data.

\section{Statistical analysis}

We used RevMan 5.025 (Nordic Cochrane Center) to carry out meta-analysis of the relative risk with $95 \%$ confidence intervals for mortality. Statistical heterogeneity was assessed using the $\mathrm{I}^{2}$ statistic, with values of $50 \%$ or more indicating a substantial level of heterogeneity. ${ }^{2223}$ We set statistical significance at a two sided $\alpha$ of 0.05 .

To avoid loss of information or choices related to results from trials with multiple intervention arms (for example, different doses of the drug), the Cochrane handbook recommends that for dichotomous outcomes, all relevant treatment arms can be amalgamated into one group by adding together the sample sizes and numbers of people with events. Hence we collapsed multiple intervention arms (different doses of tiotropium) in trials with more than one intervention group. ${ }^{24}$ To enable us to estimate relative risks we applied a continuity correction of 0.5 by the RevMan 
Table 2|Quality assessment of tiotropium mist inhaler* in randomised controlled trials included in analysis of mortality $\dagger$

\begin{tabular}{|c|c|c|c|c|c|c|}
\hline Study source & $\begin{array}{l}\text { Sequence } \\
\text { generation }\end{array}$ & $\begin{array}{l}\text { Allocation } \\
\text { concealment }\end{array}$ & Adverse event monitoring & $\begin{array}{l}\text { Drug dose (No of } \\
\text { participants) }\end{array}$ & $\begin{array}{l}\text { Withdrawal } \\
\text { rate (\%) }\end{array}$ & $\begin{array}{l}\text { Loss to } \\
\text { follow-up (\%) }\end{array}$ \\
\hline Voshaar et al $2008 \ddagger^{2729}$ & Randomised§ & Adequate & $\begin{array}{l}\text { Adverse events, vital signs, } 12 \text { lead electrocardiogram, } \\
\text { routine laboratory tests, and physical examination }\end{array}$ & $\begin{array}{l}\text { Tiotropium } 10 \mu \mathrm{g}(93) \text {; } \\
\text { tiotropium } 5 \mu \mathrm{g}(88) ; \\
\text { placebo (91) }\end{array}$ & $10 ; 8.8 ; 12.1$ & NA; NA; NA \\
\hline Voshaar et al $2008^{2829}$ & Randomised§ & Adequate & $\begin{array}{l}\text { Adverse events, vital signs, } 12 \text { lead electrocardiogram, } \\
\text { routine laboratory tests, and physical examination }\end{array}$ & $\begin{array}{l}\text { Tiotropium } 10 \mu \mathrm{g}(87) \\
\text { tiotropium } 5 \mu \mathrm{g}(92) ; \\
\text { placebo }(90)\end{array}$ & $10 ; 8.8 ; 12.1$ & $N A ; N A ; N A$ \\
\hline Bateman et al $2010^{3032}$ & $\begin{array}{l}\text { Adequate, } \\
\text { computer } \\
\text { generated }\end{array}$ & Adequate & $\begin{array}{l}\text { Adverse events, vital signs, laboratory evaluations, } \\
\text { electrocardiogram and Holter testing, and physical } \\
\text { examination. Vital status of all patients (including those } \\
\text { who discontinued prematurely) was sought and all fatal } \\
\text { events were adjudicated to primary cause of death by } \\
\text { independent expert committee }\end{array}$ & $\begin{array}{l}\text { Tiotropium } 10 \mu \mathrm{g}(332) ; \\
\text { tiotropium } 5 \mu \mathrm{g}(332) ; \\
\text { placebo (319) }\end{array}$ & $16.5 ; 16.5 ; 28.5$ & $1.5 ; 1.2 ; 3.4$ \\
\hline Bateman et al $2010^{31} 32$ & $\begin{array}{l}\text { Adequate, } \\
\text { computer } \\
\text { generated }\end{array}$ & Adequate & $\begin{array}{l}\text { Adverse events, vital signs, laboratory evaluations, } \\
\text { electrocardiogram and Holter testing, and physical } \\
\text { examination. Vital status of all patients (including those } \\
\text { who discontinued prematurely) was sought and all fatal } \\
\text { events were adjudicated as to primary cause of death by } \\
\text { independent expert committee }\end{array}$ & $\begin{array}{l}\text { Tiotropium } 10 \mu \mathrm{g}(335) \text {; } \\
\text { tiotropium } 5 \mu \mathrm{g}(338) ; \\
\text { placebo (334) }\end{array}$ & $24.1 ; 17.7 ; 34.1$ & $1.8 ; 1.4 ; 1.1$ \\
\hline Bateman et al $2010^{33} 34$ & $\begin{array}{l}\text { Adequate, } \\
\text { computer } \\
\text { generated }\end{array}$ & Adequate & $\begin{array}{l}\text { Adverse events, laboratory tests, vital signs, physical } \\
\text { examination, and electrocardiogram. Vital status of all } \\
\text { patients (including those who discontinued prematurely) } \\
\text { was sought and fatal events were adjudicated as to primary } \\
\text { cause of death by independent expert committee. } \\
\text { Prospective adjudication of mortality }\end{array}$ & $\begin{array}{l}\text { Tiotropium } 5 \mu \mathrm{g}(1989) \\
\text { placebo }(2002)\end{array}$ & $16 ; 19$ & $1.1 ; 1.4$ \\
\hline $\begin{array}{l}\text { 1205.14; } \\
\text { NCT00528996 }\end{array}$ & Unclear & Unclear & Unclear & $\begin{array}{l}\text { Tiotropium } 5 \mu \mathrm{g}(427) \text {; } \\
\text { placebo (429) }\end{array}$ & $\mathrm{NA}$; NA & NA; NA \\
\hline
\end{tabular}

NA=not available.

*Respimat (Soft Mist Inhaler; Boehringer Ingelheim).

†All trials were double blind.

†Withdrawal rates for Voshaar et al $2008^{27} 29$ and Voshaar et al $2008^{28} 29$ are reported together.

§Exact method not described but satisfactory as explicit statement regarding adequate allocation concealment.

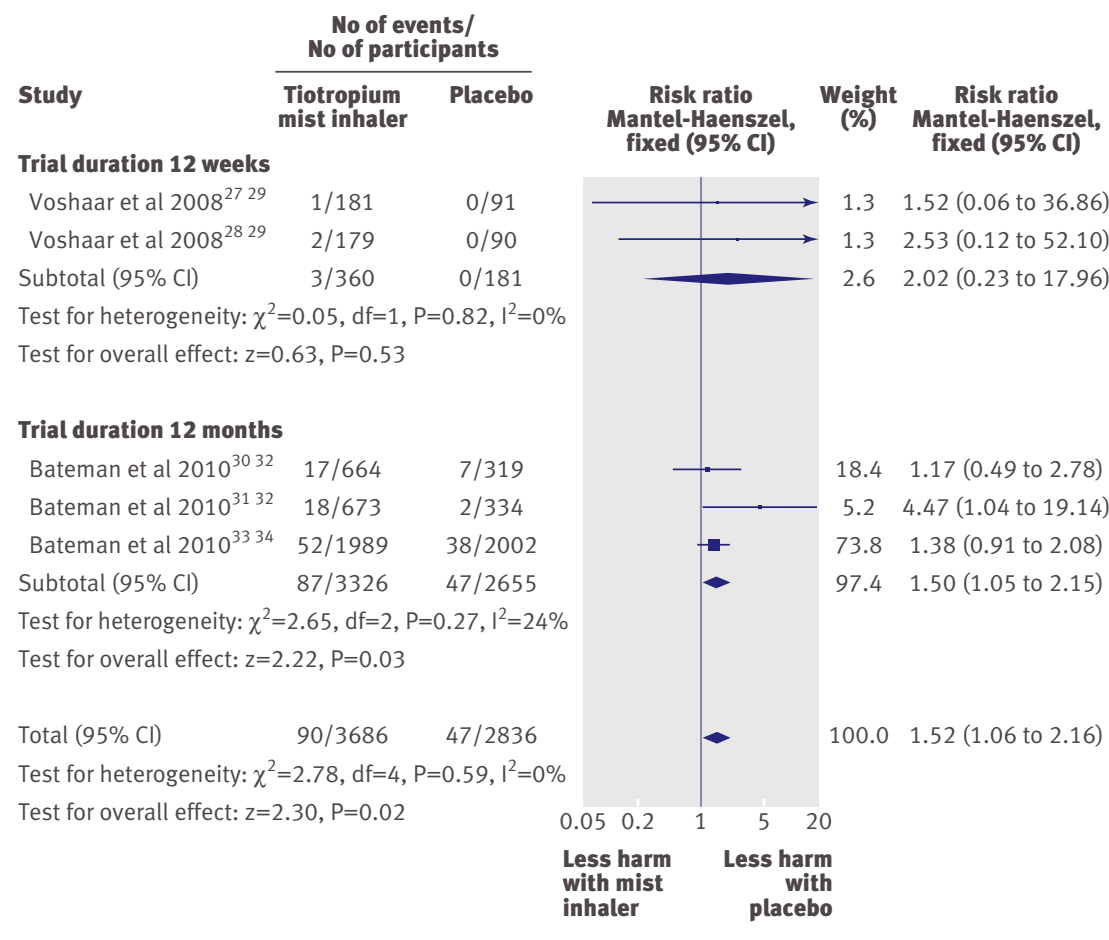

Fig 2 | Fixed effects meta-analysis of tiotropium delivered by mist inhaler (Respimat Soft Mist Inhaler; Boehringer Ingelheim) and risk of mortality in randomised controlled trials of chronic obstructive pulmonary disease software for trials that had no events in the placebo arm. We chose the fixed effect Mantel-Haenszel model as the primary method of analysis but carried out a sensitivity analysis using the random effects model. A Peto odds ratio analysis, which does not require a continuity correction, was also carried out because it provides the best confidence interval coverage and has greater power when dealing with low event rates in specific circumstances where the fixed effect assumption is valid. ${ }^{25}$ Additional predefined sensitivity analyses were done to explore the influence on effect size of different doses of tiotropium $(10 \mu \mathrm{g} v 5 \mu \mathrm{g})$, the effect of trial duration, and the influence of individual trials. We estimated the annualised number needed to treat for mortality associated with tiotropium mist inhaler by applying the pooled relative risk from the meta-analysis to the average control event rate in the long term trials, using Visual $\mathrm{Rx}$ version $2.0 .^{26}$ The number needed to treat for mortality is the number of patients with chronic obstructive pulmonary disease treated with tiotropium mist inhaler for one year, rather than placebo, associated with one additional death.

The study was carried out based on a prespecified protocol, available from the authors.

\section{RESULTS}

The search identified 57 potentially relevant articles or trial protocols for tiotropium mist inhaler (fig 1). Five placebo controlled randomised controlled trials of tiotropium mist inhaler were included in the meta- 
Table $3 \mid$ Data on mortality and cardiovascular death from randomised controlled trials of tiotropium mist inhaler*

\begin{tabular}{|c|c|c|c|c|}
\hline Study source & Drug dose, or placebo & $\begin{array}{l}\text { No of } \\
\text { participants }\end{array}$ & $\begin{array}{l}\text { All cause } \\
\text { mortality }\end{array}$ & Cardiovascular death \\
\hline Voshaar et al $2008^{2729}$ & $\begin{array}{l}\text { Tiotropium } 10 \mu \text { g; tiotropium } 5 \mu \text {; } \\
\text { placebo }\end{array}$ & $93 ; 88 ; 91$ & $1 ; 0 ; 0$ & $0 ; 0 ; 0$ \\
\hline Voshaar et al $2008^{2829}$ & $\begin{array}{l}\text { Tiotropium } 10 \mu \text { g; tiotropium } 5 \mu \mathrm{g} \text {; } \\
\text { placebo }\end{array}$ & $87 ; 92 ; 90$ & $1 ; 1 ; 0$ & $0 ; 0 ; 0$ \\
\hline Bateman et al $2010^{30} 32$ & $\begin{array}{l}\text { Tiotropium } 10 \mu g \text {; tiotropium } 5 \mu \mathrm{g} \text {; } \\
\text { placebo }\end{array}$ & $332 ; 332 ; 319$ & $8 ; 9 ; 7$ & $\begin{array}{l}\text { Study } 254 / 255 \text { combined } 5 \mu \text { and } 10 \mu g \\
\text { cardiovascular deaths }(n=8) \text { : due to cardiac } \\
\text { failure }(n=1) \text {, myocardial infarction/coronary } \\
\text { insufficiency }(n=6) \text {, and stroke }(n=1)\end{array}$ \\
\hline Bateman et al $2010^{31} 32$ & $\begin{array}{l}\text { Tiotropium } 10 \mu \mathrm{g} \text {; tiotropium } 5 \mu \mathrm{g} \text {; } \\
\text { placebo }\end{array}$ & $335 ; 338 ; 334$ & $11 ; 7 ; 2$ & $\begin{array}{l}\text { Cardiovascular death with placebo: stroke } \\
(\mathrm{n}=1)\end{array}$ \\
\hline Bateman et al $2010^{3334}$ & 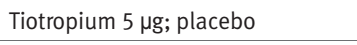 & 1989; 2002 & $52 ; 38$ & $22 ; 12$ \\
\hline $\begin{array}{l}\text { 1205.14; } \\
\text { NCT00528996 }\end{array}$ & Tiotropium 5 g; placebo & $427 ; 429$ & $2 ; 5$ & $N A ; N A$ \\
\hline
\end{tabular}

*Respimat Soft Mist Inhaler (Boehringer Ingelheim).

analysis of the primary outcome. ${ }^{27-34}$ One additional six month trial from another investigational drug programme in chronic obstructive pulmonary disease reported preliminary data on mortality with tiotropium mist inhaler $5 \mu \mathrm{g}$ compared with placebo without additional detail on trial characteristics. ${ }^{35}$ This trial was therefore not included in the primary analysis but was evaluated in a sensitivity analysis. Table 1 shows the characteristics of the trials.

The five trials included 6522 participants, of whom 3686 received tiotropium mist inhaler and 2836 a placebo. $^{27-34}$ In these five trials, 2839 participants received tiotropium $5 \mu \mathrm{g} .{ }^{27-34}$ Additionally, four of these trials also included another randomised arm in

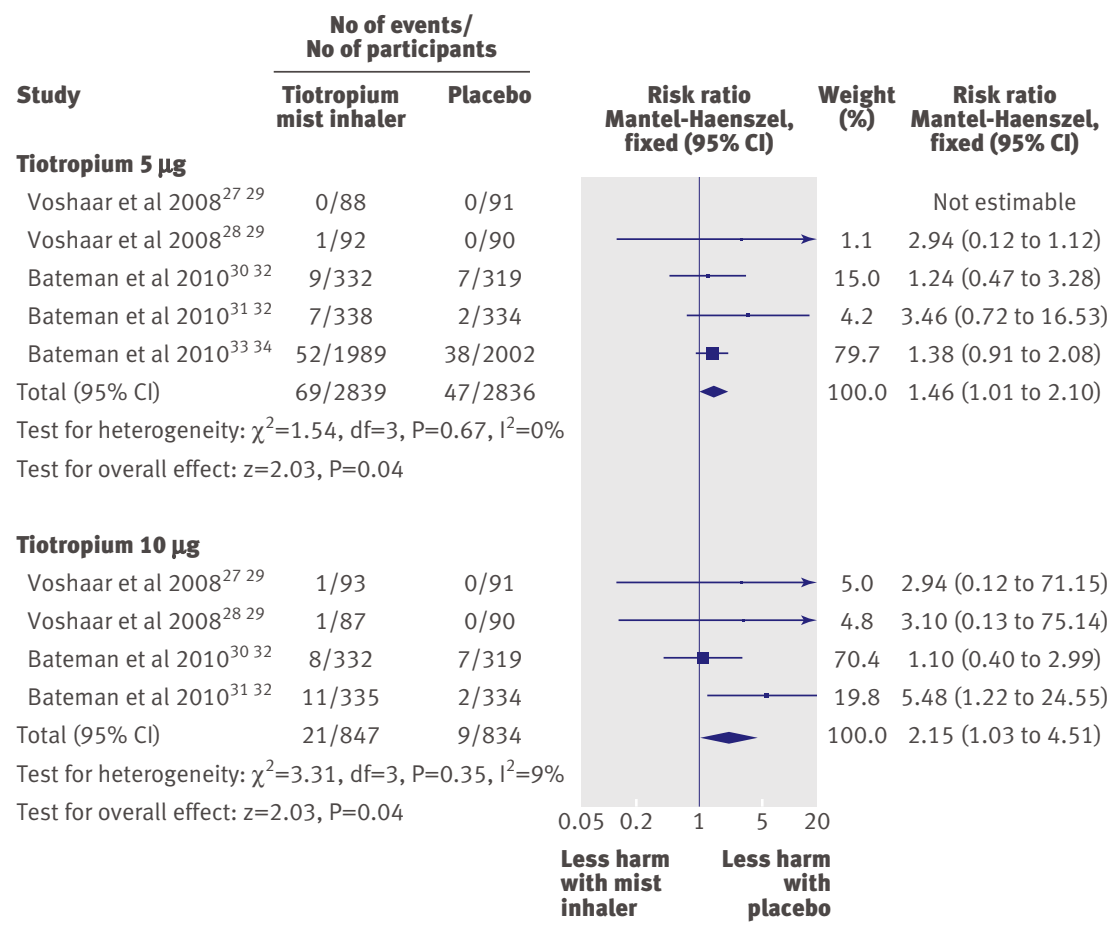

Fig 3 | Meta-analysis of tiotropium delivered by mist inhaler (Respimat Soft Mist Inhaler; Boehringer Ingelheim) $5 \mu \mathrm{g}$ and $10 \mu \mathrm{g}$ and risk of mortality in randomised controlled trials of chronic obstructive pulmonary disease which 847 participants received tiotropium mist inhaler $10 \mu \mathrm{g} .{ }^{27-32}$ Two of the trials were short term, with a duration of 12 weeks, ${ }^{27-29}$ and three were long term, with a duration of one year. ${ }^{30-34}$

All the trials were double blind, with adequate allocation concealment (table 2). ${ }^{27-34}$ Two of the short term trials stated they were randomised but did not give the specific method of sequence generation, although they did state that investigators and participants were blinded to the process of randomisation. ${ }^{27-29}$ However, since all the trials were part of the same investigational programme, it is unlikely that methods of randomisation (remote computer generated lists of random numbers) would be different. Trial quality was satisfactory and all five trials were judged to be at low risk of bias (adequate sequence generation or allocation concealment, double blinding, and clear reporting of loss to follow-up).

To reduce the chance of bias from differential discontinuation of participants between the tiotropium and placebo arms, retrospective mortality ascertainment on participants who discontinued the assigned intervention was carried out at the request of regulatory agencies for the two long term trials, after safety concerns about tiotropium. ${ }^{30-3236}$ The cause specific mortality estimates from these two trials ${ }^{30-32}$ were combined and adjudicated in the FDA review. ${ }^{720}$ Subsequently, one long term trial of tiotropium mist inhaler ascertained mortality prospectively on all randomised participants, including those who withdrew from the trial. $^{3334}$

\section{Primary outcome}

Table 3 shows the data on mortality from the randomised controlled trials. Overall, the tiotropium mist inhaler was associated with a significantly increased risk of mortality compared with placebo (five trials, 90/3686 $v$ 47/2836; relative risk 1.52, 95\% confidence interval 1.06 to $2.16 ; \mathrm{P}=0.02) .{ }^{27-34}$ Evidence of statistical heterogeneity for mortality was lacking among the trials $\left(\mathrm{I}^{2}=0 \%\right){ }^{27-34}$

Because the trials were of different duration a forest plot illustrates the treatment effects for trials up to three months and the longer term trials for one year (fig 2). 


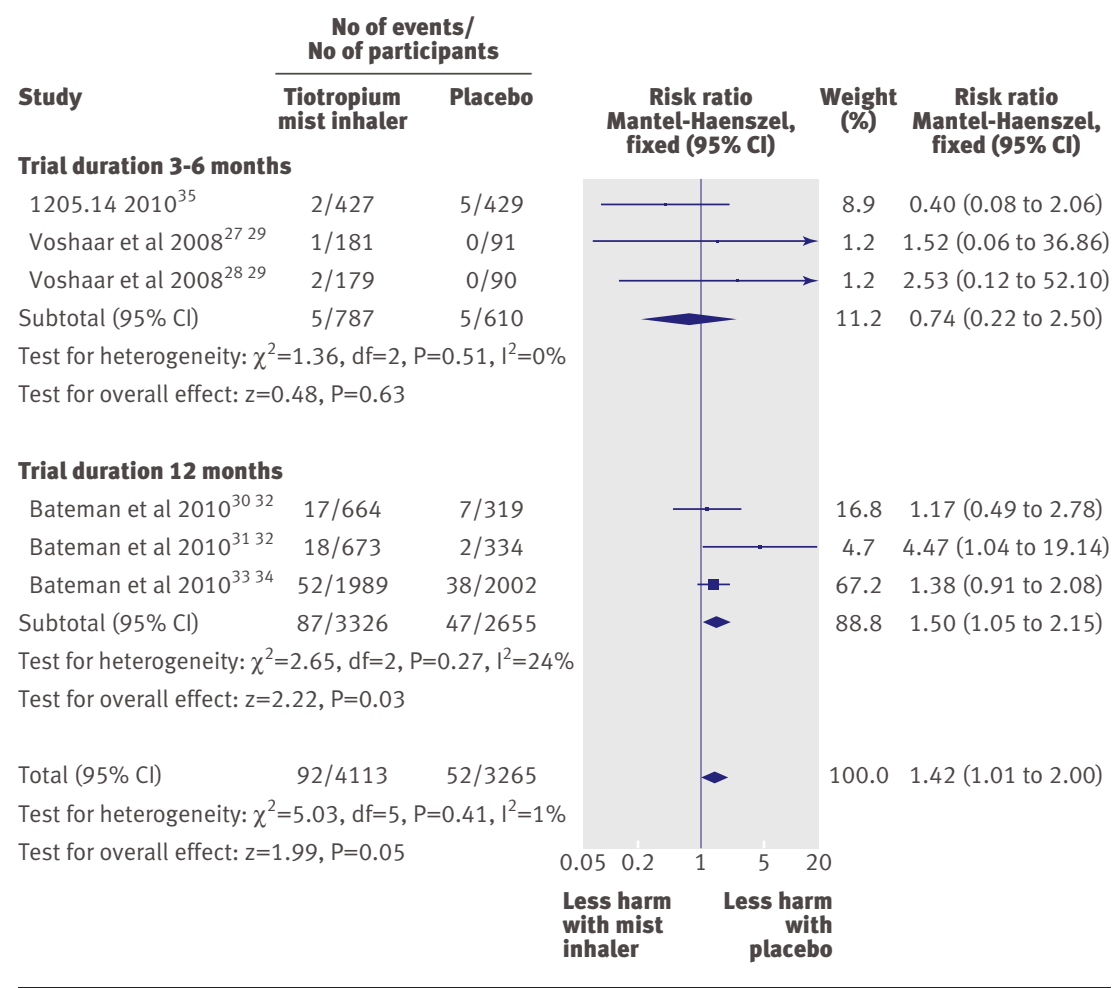

Fig 4 Sensitivity analysis of tiotropium delivered by mist inhaler (Respimat Soft Mist Inhaler; Boehringer Ingelheim) and risk of mortality in randomised controlled trials of chronic obstructive pulmonary disease after including data from additional trial ${ }^{35}$

The mortality estimate was primarily driven by the three trials of 12 months' duration $(1.50,1.05$ to 2.15 ; $\left.\mathrm{P}=0.03 ; \mathrm{I}^{2}=24 \%\right) .{ }^{30-34}$

\section{Effect of different doses of tiotropium}

Compared with placebo, tiotropium $5 \mu \mathrm{g}$ was associated with a $46 \%$ increased risk of mortality in the five trials $\left(1.46,1.01\right.$ to $\left.2.10 ; \mathrm{P}=0.04 ; \mathrm{I}^{2}=0 \%\right)$, whereas the $10 \mu \mathrm{g}$ dose was associated with a doubling of the relative risk in four trials $(2.15,1.03$ to $4.51 ; \mathrm{P}=0.04$; $\mathrm{I}^{2}=9 \%$ ), (fig 3). ${ }^{27-32}$ A direct comparison of the two doses using a fixed effect meta-analysis from four trials showed an increased risk of overall mortality associated with $10 \mu \mathrm{g}$ tiotropium that did not reach significance $(1.23,0.66$ to $2.30 ; \mathrm{P}=0.51) .{ }^{27-32}$

\section{Sensitivity analysis}

Peto method versus Mantel-Haenszel method-Sensitivity analysis based on the Peto odds ratio for overall mortality in the five included studies showed results similar to the Mantel-Haenszel fixed effect analysis: Peto odds ratio $1.53(95 \%$ confidence interval 1.08 to 2.16$), \mathrm{P}=$ $0.02 .^{27}$

Fixed effect versus random effects - Sensitivity analysis using the random effects model for overall mortality in the five trials showed results similar to the fixed effect model: relative risk 1.45 (95\% confidence interval 1.02 to 2.07$), \mathrm{P}=0.04$. $^{27-34}$

Inclusion of additional trial-The inclusion of data from the additional trial ${ }^{35}$ did not significantly change the overall results (six trials, 1.42, 1.01 to $2.00 ; \mathrm{P}=0.05$; fig 4), but reduced the relative risk for the $5 \mu \mathrm{g}$ dose to 1.36 ( 0.96 to $1.94 ; \mathrm{P}=0.09)$.

\section{Secondary outcome}

Although the numbers for cardiovascular death were sparse (table 3), tiotropium was associated with a significantly increased relative risk in the five trials $(2.05$, 1.06 to $3.99 ; \mathrm{P}=0.03 ; \mathrm{I}^{2}=0 \%$; fig 5$) .{ }^{23-30}$

\section{Number needed to treat for mortality}

Applying the relative risk estimate of 1.46 (95\% confidence interval 1.01 to 2.10 ) from the meta-analysis of the $5 \mu \mathrm{g}$ dose to the control event rate of $1.76 \%$ per year for mortality in the long term trials, the annualised number needed to treat for mortality associated with tiotropium was estimated at 124 (95\% confidence interval 52 to 5682) - that is, one excess death would be expected for every 124 patients treated with $5 \mu \mathrm{g}$ of tiotropium for one year.

\section{DISCUSSION}

This meta-analysis shows that tiotropium delivered with the Respimat Soft Mist Inhaler (Boehringer Ingelheim) is associated with a statistically significant increased risk of mortality in patients with chronic obstructive pulmonary disease. Our findings raise the possibility of a dose-response effect, although the relatively sparse data prevent us from drawing firm conclusions.

\section{Strengths of the study}

The validity of our pooled estimates were enhanced by several features of our analysis. Our data represent the complete set of parallel group trials of more than 30 days' duration carried out by the manufacturer for tiotropium mist inhaler compared with placebo that was submitted to the US FDA. The trials were done in a standardised manner by a single sponsor and the risk of bias was generally low, thus enhancing the validity of pooling in a meta-analysis. Trial investigators managed complete capture of the mortality outcome in the long term trials, and took onerous steps to ascertain the vital status of all randomised patients, even if they had discontinued treatment, thus minimising the risk of bias from differential follow-up and selective outcome reporting. The finding of the increased risk remains robust to various sensitivity analyses such as the use of the random effects model and the inclusion of preliminary data from another unpublished trial.

Alternative explanations exist for these unfavourable findings. In one unpublished study, the increase in mortality was attributed by the sponsor to a baseline imbalance in risk created by randomisation, or an unusually low rate of mortality in the placebo arm of these trials. ${ }^{37}$ However, a systematic failure of randomisation is highly unlikely, as both the tiotropium and the placebo groups had comparable baseline characteristics in all the trials, with adequate allocation concealment during randomisation. It is unclear why patients using the placebo inhalers would have a $33 \%$ lower mortality than those receiving active treatment. The excess death 


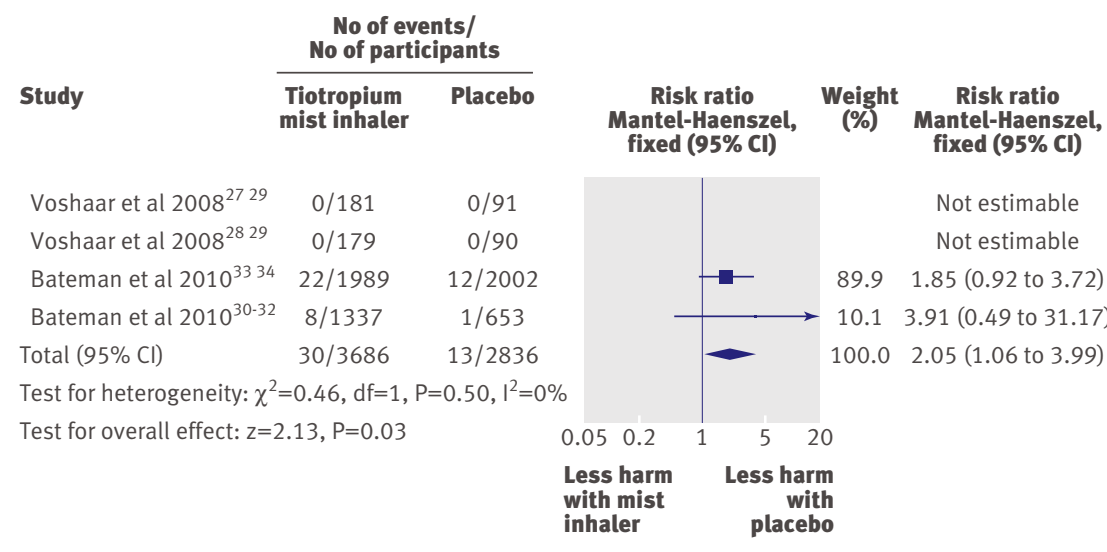

Fig 5 | Meta-analysis of tiotropium delivered by mist inhaler (Respimat Soft Mist Inhaler;

Boehringer Ingelheim) and risk of cardiovascular death in randomised controlled trials

rates could be due to chance; however, the robustness of the data to sensitivity analysis and generally low risk of bias indicates that this is a safety signal meriting both caution and further investigation.

Biological plausibility

The Lung Health Study reported a significantly higher rate of admissions to hospital for malignant arrhythmias in participants with mild to moderate chronic obstructive pulmonary disease randomised to the anticholinergic inhaler. ${ }^{38}$ Inhaled tiotropium is absorbed systemically and excreted in the urine. ${ }^{39}$ Orally administered anticholinergic drugs are associated with cardiac arrhythmias. ${ }^{40}$ This information provides a biologically plausible mechanism for anticholinergic inhalers causing sudden cardiac death. Patients with pre-existing arrhythmias seem to be at the highest risk of death with tiotropium mist inhaler. ${ }^{37}$

Patients using the mist inhaler may have clinically relevant, higher peak concentrations and overall exposure to tiotropium, providing a plausible mechanism of differential toxicity and a dose-response relation when compared with the powder formulation used with the Handihaler (Boehringer Ingelheim). In one study, the peak plasma concentration (Cmax) of tiotropium powder $18 \mu \mathrm{g}$ was $8.49 \mathrm{pg} / \mathrm{mL}$ compared with $11.5 \mathrm{pg} / \mathrm{mL}$ and $26.4 \mathrm{pg} / \mathrm{mL}$ for $5 \mu \mathrm{g}$ and $10 \mu \mathrm{g}$ of the mist inhaler, respectively, although the statistical significance of these data was not reported. ${ }^{3}$ Similarly, the area under the curve for overall exposure to tiotropium showed that patients receiving tiotropium powder $18 \mu \mathrm{g}$ had a lower mean exposure to the drug: 55.9 $\mathrm{pg} \mathrm{h} / \mathrm{mL}$ compared with $64.7 \mathrm{pg} \mathrm{h} / \mathrm{mL}$ and $146 \mathrm{pg} \mathrm{h} /$ $\mathrm{mL}$ for $5 \mu \mathrm{g}$ and $10 \mu \mathrm{g}$ of the mist inhaler, respectively.

\section{Comparison with other reports}

Our finding should be interpreted in the context of other recent reports. ${ }^{41-43} \mathrm{~A}$ meta-analysis driven mainly by data from the UPLIFT trial reported no significant increase in cardiovascular events with tiotropium. ${ }^{42}$ However, 18 of the 19 trials were based on the powder formulation, and only one small study on the mist inhaler ${ }^{29}$ contributed data to the meta- analysis. Another meta-analysis of 30 trials of tiotropium $^{43}$ indicated that the drug was associated with reductions in cardiovascular events or mortality, but a separate assessment of the two different products (powder and mist inhaler) was not reported. Moreover, this meta-analysis did not include the largest trial of the mist inhaler, ${ }^{33}$ and it is unclear if deaths among participants who withdrew prematurely in three trials were considered. ${ }^{283031}$

\section{Limitations of the review}

Our analysis has limitations, which mainly reflect the quality of reported data. Differences exist in the populations studied, doses of tiotropium using the mist inhaler, and length of follow-up. The estimates are imprecise owing to the fairly low event rates. We could not examine cause specific mortality in great depth because of the lack of details in the reported data. Similarly, cardiovascular death was not a prespecified outcome, and the analysis relies on post hoc classification and adjudication. We did not have access to individual patient data to allow analyses of time to event.

\section{Unanswered questions and future research}

An ongoing two year head to head trial between tiotropium mist inhaler $2.5 \mu \mathrm{g}$ (two puffs of $1.25 \mu \mathrm{g}$ each) and tiotropium powder $5 \mu \mathrm{g}$ (two puffs of $2.5 \mu \mathrm{g}$ each) and $18 \mu \mathrm{g}$ has been designed to investigate these safety issues and should further clarify these uncertainties. ${ }^{44}$ The primary outcomes include exacerbation of chronic obstructive pulmonary disease and overall mortality as well as a secondary outcome measure of major adverse cardiovascular events. Clinical trials of chronic obstructive pulmonary disease should be designed to include both efficacy and cardiovascular disease mortality (including sudden death) as co-primary outcome measures. Further studies should clarify the effects of long acting inhaled anticholinergics on cardiovascular events and mortality among vulnerable subgroups at the highest risk of systemic anticholinergic effects, such as those with pre-existing arrhythmias, cardiomegaly, or moderate to severe renal impairment who are typically excluded from trials. A precautionary warning about this possible association has been added to the package insert for Respimat in New Zealand. ${ }^{45}$ The UK Medicines and Healthcare Products Regulatory Agency has also provided recent guidance on this concern. ${ }^{4647}$

\section{Conclusions}

Our meta-analysis explains safety concerns by regulatory agencies regarding the possibility of an increased risk of mortality associated with tiotropium mist inhaler in patients with chronic obstructive pulmonary disease. In accordance with guidance from the Medicines and Healthcare Products Regulatory Agency, clinicians should inform patients about the possibility of this increased risk and exercise caution when prescribing tiotropium mist inhaler, particularly in patients with possible underlying cardiac disease. 


\section{WHAT IS ALREADY KNOWN ON THIS TOPIC}

Tiotropium is used for symptomatic improvement in patients with chronic obstructive pulmonary disease

Tiotropium has no documented effect on the decline in lung function and has not been shown to have a survival benefit in patients with chronic obstructive pulmonary disease

Previous studies have suggested the possibility of an adverse cardiovascular effect associated with tiotropium

\section{WHAT THIS STUDY ADDS}

In this systematic review and meta-analysis of 6522 patients with chronic obstructive pulmonary disease tiotropium mist inhaler was associated with a $52 \%$ increased risk of all cause mortality compared with placebo

The study suggests a possible dose-response increased risk of mortality associated with tiotropium mist inhaler

The study showed an increased risk of cardiovascular mortality associated with tiotropium mist inhaler pulmonary disease, Saskatchewan, Canada. Ann Epidemiol 2006;16:63-70.

9 Singh S, Loke YK, Furberg CD. Inhaled anticholinergics and risk of major adverse cardiovascular events in patients with chronic obstructive pulmonary disease: a systematic review and metaanalysis. JAMA 2008;300:1439-50. (Erratum in JAMA 2009;301:1227-30.)

10 Ogale SS, Lee TA, Au DH, Boudreau DM, Sullivan SD. Cardiovascular events associated with ipratropium bromide in COPD. Chest 2010;137:13-9.

11 Lee TA, Pickard AS, Au DH, Bartle B, Weiss K. Risk for death associated with medications for recently diagnosed chronic obstructive pulmonary disease. Ann Intern Med 2008;149:380-9.

12 Macie C, Wooldrage K, Manfreda J, Anthonisen N. Cardiovascular morbidity and the use of inhaled bronchodilators. Int J Chron Obstruct Pulmon Dis 2008;3:163-9.

13 Ringback T, Viskum K. Is there any association between inhaled ipratropium and mortality in patients with COPD and asthma? Respir Med 2003;97:264-72.

14 Guite HF, Dundos R, Burney PGI. Risk factors for death from asthma, chronic obstructive pulmonary disease, and cardiovascular disease after a hospital admission for asthma. Thorax 1999;54:301-7.

15 Tashkin DP, Celli B, Senn S, Burkhart D, Kesten S, Menjoge S, et al: for the UPLIFT Study Investigators. A 4-year trial of tiotropium in chronic obstructive pulmonary disease. $N$ Engl J Med 2008;359:1543-54

16 Mclvor RA. Tiotropium and chronic obstructive airways disease. $B M$ 2010;340:c833.

Contributors: SS and YKL conceived and designed the study, drafted the manuscript, acquired the data, and carried out the statistical analysis. All authors analysed and interpreted the data and critically revised the manuscript for important intellectual content. CDF supervised the study. SS had full access to all of the data in the study and takes responsibility for the integrity of the data and the accuracy of the data analysis and is guarantor. SS and YKL contributed equally to this work.

Funding: SS is supported by a grant from the National Center for Research Resources, a component of the National Institutes of Health (No 1KL2RR025006-03), and National Institutes of health Roadmap for Medical Research. The contents of this study are solely the responsibility of the authors and do not necessarily represent the official view of National Center for Research Resources or the National Institutes of Health. The design and conduct of the study; collection, management, analysis, and interpretation of the data; and preparation, review, or approval of the manuscript was independent of any sources of funding. Competing interests. All authors have completed the Unified Competing Interest form at www.icmje.org/coi_disclosure.pdf (available on request from the corresponding author) and declare: no support from any companies for the submitted work; PE has received about $\$ 30000$ ( $118000 ; € 21000$ ) from Pfizer to review the quality of spirometry tests done for an international study of varenicline for smoking cessation in patients with chronic obstructive pulmonary disease; no author has nonfinancial interests that may be relevant to the submitted work: no other relationships or activities that could appear to have influenced the submitted work.

Ethical approval: Not required

Data sharing: No additional data available.

1 World Health Organization. Global burden of disease 2004 update. WHO, 2008.

2 Van den Bruel A, Gailly J, Neyt M. Does tiotropium lower exacerbation and hospitalization frequency in COPD? BMC Pulm Med 2010;10:50.

3 Van Noord JA, Cornelissen PJ, Aumann JL, Platz J, Mueller A, Fogarty C The efficacy of tiotropium administered via Respimat ${ }^{\circledR}$ Soft Mist Inhaler or HandiHaler in COPD patients. Respir Med 2009;103:22-9.

4 Scottish Medicines Consortium. Tiotropium (Spiriva-Respimat). SMC drug ID 411/07. 2011. http://www.scottishmedicines.org.uk/files/ tiotropium respimat inhaler Spiriva-

Respimat_Abbreviated_FINAL_Nov_2007_for_website.pdf.

5 Information Centre for Health and Social Care. Prescriptions cost analysis, England-2009. 2011. www.ic.nhs.uk/pubs/ prescostanalysis 2009

6 NHS National Services Scotland. Prescriptions cost analysis, Scotland. 2009. www.isdscotland.org/isd/information-andstatistics.jsp?

pContent $\mid D=2241 \&$ p_applic=CCC\&p_service=Content.show\&.

7 Division of Pulmonary-Allergy Drugs Advisory Committee and Office of Surveillance and Epidemiology, US Food and Drug Administration. FDA briefing document. 2009. www.fda.gov/downloads/ AdvisoryCommittees/CommitteesMeetingMaterials/Drugs/ Pulmonary-AllergyDrugsAdvisoryCommittee/UCM190463.pdf.

8 Curkendall SM, DeLuise C, Jones JK, Lanes S, Stang MR, Goehring E Jr, et al. Cardiovascular disease in patients with chronic obstructive boehringer-ingelheim.com/com/Home/TrialResults/index.jsp.

18 ClinicalTrials.gov. Home page. 2011. www.clinicaltrials.gov.

19 ClinicalStudyResults.org. Home page. 2011. www. clinicalstudyresults.org.

20 Boehringer Ingelheim. Briefing document. 2009. www.fda.gov/ downloads/AdvisoryCommittees/CommitteesMeetingMaterials/ Drugs/Pulmonary-AllergyDrugsAdvisoryCommittee/UCM190466. pdf.

21 Loke YK, Price D, Herxheimer A. Adverse effects. In: Higgins JPT, Green S, eds. Cochrane handbook for systematic reviews of interventions Version 5.0.0 [updated February 2008]. The Cochrane Collaboration, 2008. Available from www.cochrane-handbook.org.

22 Higgins JP, Thompson SG, Deeks JJ, Altman DG. Measuring inconsistency in meta-analyses. BMJ 2003;327:557-60.

23 Ioannidis JP, Patsopoulos NA, Evangelou E. Uncertainty in heterogeneity estimates in meta-analyses. BMJ 2007;335:914-6.

24 Higgins JP, Deeks JJ, Altman DG. Special topics in statistics. In: Higgins JPT, Green S (eds). Cochrane handbook for systematic reviews of interventions Version 5.0.2 [updated September 2009]. The Cochrane Collaboration,

2009. Available from www.cochrane-handbook.org.

25 Bradburn MJ, Deeks IJ, Berlin JA, Russell Localio A. Much ado about nothing: a comparison of the performance of meta-analytical methods with rare events. Stat Med 2007;26:53-77.

26 Cates Cl. Simpson's paradox and calculation of number needed to treat from meta-analysis. BMC Med Res Methodol 2002;2:1.

27 ClinicalTrials.gov. 12 week comparison of 5 Mcg and 10 Mcg of Tiotropium/Respimat ${ }^{\circledR}$, placebo and Ipratropium MDI in COPD. NCT00239473. 2010. http://clinicaltrials.gov/ct2/show/ NCT00239473.

28 ClinicalTrials.gov. 12 week comparison of $5 \mathrm{Mcg}$ and $10 \mathrm{Mcg}$ of Tiotropium/Respimat ${ }^{\circledR}$, placebo and Ipratropium MDI in COPD. NCT00240435. 2010. http://clinicaltrials.gov/ct2/show/ NCT00240435.

29 Voshaar T, Lapidus R, Maleki-Yazdi R, Timmer W, Rubin E, Lowe L, et al. A randomized study of tiotropium Respimat ${ }^{\circledR}$ Soft Mist inhaler vs ipratropium pMDI in COPD. Respir Med 2008;102:32-41.

30 ClinicalTrials.gov. Tiotropium/Respimat ${ }^{\circledR}$ one-year study. NCT00168844. 2010. http://clinicaltrials.gov/ct2/show/ NCT00168844. NCT00168831. 2010. http://clinicaltrials.gov/ct2/show/ NCT00168831.

32 Bateman E, Singh D, Smith D, Disse B, Towse L, Massey D, et al. Efficacy and safety of tiotropium Respimat ${ }^{\circledR}$ SMI in COPD in two 1 year randomized studies. Int J Chron Obstruct Pulmon Dis 2010;5:197-208.

33 ClinicalTrials.gov. Tiotropium/Respimat ${ }^{\circledR}$ one-year study in COPD. NCT00387088. 2010. http://clinicaltrials.gov/ct2/show/ NCT00387088.

34 Bateman ED, Tashkin D, Siafakas N, Dahl R, Towse L, Massey D, et al. patients. Respir Med 2010;104:1460-72.

35 ClinicalTrials.gov. An efficacy and safety study to compare three doses of BEA 2180 BR to tiotropium and placebo in the Respimat ${ }^{\circledR}$
17 Boehringer Ingelheim International. Trial results. 2011. http://trials.

31 ClinicalTrials.gov. Tiotropium/Respimat ${ }^{\circledR}$ one-year study. A one-year trial of tiotropium Respimat ${ }^{\circledR}$ plus usual therapy in COPD 
inhaler. NCT00528996. 2010. http://clinicaltrials.gov/ct2/show/ NCT00528996.

36 Boehringer Ingelheim International. A retrospective collection of vital status and pulmonary medication usage data for patients with chronic obstructive pulmonary disease (COPD) who withdrew prematurely from either of two one-year trials $(205.254,205.255)$ of tiotropium inhalation solution delivered by the Respimat $₫$ inhaler. 2009. http://trials.boehringer-ingelheim.com/res/trial/data/pdf/ 205.392_U08-3209.pdf.

37 Boehringer Ingelheim International. Tiotropium (Spiriva®) Respimat@: evaluation of fatal events-February 2010. 2010. http:// trials.boehringer-ingelheim.com/res/trial/data/pdf/

Pooled Analysis U10-3255-01.pdf.

38 Anthonisen NR, Connett JE, Enright PL, Manfreda J: for the Lung Health Study Research Group. Hospitalizations and mortality in the Lung Health Study. Am J Respir Crit Care Med 2002;166:333-9.

39 Caillaud D, Le Merre C, Martinat Y, Aguilaniu B, Pavia D. A dose ranging study of tiotropium delivered via Respimat Soft Mist Inhaler or HandiHaler in COPD patients. Int J Chron Obstruct Pulmon Dis 2007;2:559-65.

40 Alzayer R, Hughes J, Parson R, Lee YP. Comparison of risk of neurovascular and cardiovascular side effects between tiotropium and other anticholinergic agents. Qual Prim Care 2010;18:189-99.

41 Rodrigo GJ, Castro-Rodriguez JA, Nannini LJ, Plaza Moral V, Schiavi EA. Tiotropium and risk for fatal and nonfatal cardiovascular events in patients with chronic obstructive pulmonary disease: systematic review with meta-analysis. Respir Med 2009;103:1421-9.

42 Celli B, Decramer M, Kesten S, Liu D, Mehra S, Tashkin DP: UPLIFT Study Investigators. Mortality in the 4-year trial of tiotropium (UPLIFT) in patients with chronic obstructive pulmonary disease. Am J Respir Crit Care Med 2009;180:948-55.

43 Celli B, Decramer M, Leimer I, Vogel U, Kesten S, Tashkin DP. Cardiovascular safety of tiotropium in patients with COPD. Chest 2010;137:20-30.

44 Comparison of tiotropium in the HandiHaler versus the Respimat ${ }^{\circledR}$ in chronic obstructive pulmonary disease. NCT01126437. 2011. http://clinicaltrials.gov/ct2/show/NCT01126437? term=tiotropium \&rank=21.

45 Boehringer Ingelheim. Data sheet. Spiriva ${ }^{\circledR}$ Respimat $^{\circledR}$ tiotropium 2.5 mcg. 2010. www.medsafe.govt.nz/Profs/Datasheet/s/ spirivarespimatinh.pdf.

46 Electronic Medicines Compendium. Spiriva Respimat ${ }^{\circledR-}$ summary of product characteristics. 2011. www.medicines.org.uk/EMC/ medicine/20547/PIL/Spiriva\%20Respimat\%202.5\%20micrograms \%20solution\%20for\%20inhalation/.

47 Medicines and Healthcare Products Regulatory Agency. Drug safety update. 2010. www.mhra.gov.uk/home/groups/dsu/documents/ publication/con099854.pdf.

Accepted: 8 April 2011 